JURNAL PENDIDIKAN, p-ISSN 2715-095X, e-ISSN 2686-5041

Volume 29, No.2, Juli 2020 (121-126)

Online: http://journal. univetbantara. ac. id/index. php/.jp

\title{
Peningkatan Kompetensi Menganalisis Vektor dengan Model Pembelajaran Jigsaw Bagi Siswa Kelas X MIPA 4 Semester 1 SMA Negeri 1 Tawangsari Tahun Pelajaran 2019/2020
}

\author{
Muh Muhtar \\ Guru SMA Negeri 1 Tawangsari Kabupaten Sukoharjo,Email: muhmuhtar53@gmail.com
}

\begin{abstract}
Abstrak: Penelitian ini bertujuan untuk mengetahui seberapa besar peningkatan kompetensi menganalis vektor, dan mengetahui perubahan keaktifan siswa setelah pambelajaran menggunakan model pembelajaran tipe jigsaw. Penelitian ini merupakan Penetian Tindakan Kelas (Classroom Action Research) dengan model pembelajaran kooperatif tipe Jigsaw yang dilaksanakan dua siklus. Setiap siklus diawali dengan tahap persiapan kemudian dilanjutkan dengan tahap pelaksanaan siklus yang terdiri dari perencanaan tindakan, pelaksanaan tindakan,observasi, evaluasi dan refleksi. Metode pengumpulan data yang digunakan adalah tes dan observasi. Subyek penelitian adalah siswa kelas X MIPA 4 semester 1 SMA Negeri 1 Tawangsari tahun pelajaran 2019/2020. Berdasarkan hasil penelitian dapat disimpulkan bahwa (1) Proses pembelajaran dengan model pembelajaran tipe jigsaw mampu meningkatkan prestasi belajar siswa. (2). Besar peningkatan kompetensi menganalisis vektor dengan rincian nilai rata-rata nilai Siklus 1 sebesar 75 dan Siklus 2 rata-rata sebesar 80 . Sehingga peningkatan dari Siklus 1 ke Siklus 2 adalah 5\%. (3) Pembelajaran dengan model pembelajaran tipe jigsaw pada kompetensi menganalisis vektor mengalami perubahan keaktifan siswa. Pada siklus 1 menjadi 62 (sedang) dan pada siklus 2 menjadi 76 (baik).
\end{abstract}

Kata-kata Kunci: vektor, jigsaw

\section{Improvement competence in analysing vector by "jigsaw" model The learning for class X MIPA4 Students of SMA Negeri 1 Tawangsari Semester 1 for 2019/2020 Academic Year}

\section{Muh Muhtar}

Teacher of SMA Negeri 1 Tawangsari,Sukoharjo Regency,email:muhmuhtar53@gmail.com

\begin{abstract}
This research is to find out how big the competence increase in analysing vector and to find out the change of students being active after the learning using "jigsaw" model.This research is a Classroom Action Research using jigsaw type cooperative learning carries in 2 cycles. Each cycle is started by preparing than continud by the step of cycle. Implementation consisting of planning the step. Implementing the steps, observation consisting of planing the step, observation, evoluation and reflection. The metode of data collection used is by using test and observation. The subjects of research are the student class X MIPA 4 semester 1 state senior High School 1 Tawangsari of students years 2019/2020.Based on the result of the research it can be included that (1) The learning proses using the model of jigsaw learning type can increase student achievement. (2) The ringe of competence increase in analysing vektor with value detail of everage value cycle 1 is 77 and cycle 2 is everagely 82. So the increase of cycle 1 to cycle 2 is 5\%. (3) The learning using the model of jigsaw type learning in competence of analysing vektor, gets change in students being active. On cycle 1 became 65 (everage) and on cycle 2 becames 75 (good).
\end{abstract}

Keywords: vector, jigsaw 


\section{Pendahuluan}

Fisika merupakan salah satu cabang Ilmu Pengetahuan Alam (IPA) yang mendasari perkembangan teknologi maju dan konsep hidup harmonis dengan alam. Hal ini sejalan dengan pesatnya perkembangan di bidang teknologi informasi dan komunikasi dewasa ini. Pada tingkat SMA/MA, fisika dipandang penting untuk diajarkan sebagai mata pelajaran tersendiri dengan beberapa pertimbangan. Pertama, untuk memberikan bekal ilmu kepada peserta didik. Mata pelajaran Fisika dimaksudkan sebagai wahana untuk menumbuhkan kemampuan berpikir yang berguna untuk memecahkan masalah di dalam kehidupan seharihari. Kedua, untuk tujuan yang lebih khusus yaitu membekali peserta didik pengetahuan, pemahaman dan sejumlah kemampuan yang dipersyaratkan untuk memasuki jenjang pendidikan yang lebih tinggi serta mengembangkan ilmu dan teknologi. Kondisi yang terjadi di lapangan bahwa Kompetensi menganalisis vektor siswa kelas X MIPA 4 SMA Negeri 1 Tawangsari masih di bawah KKM. Hal ini disebabkan siswa yang kurang berminat, kurang tertarik, merasa kesulitan dalam kompetensi menganalisis vektor selain itu, guru kurang dapat memotivasi siswa untuk lebih menyenangi pembelajarannya, bahkan pemilihan metode pembelajaran yang kurang tepat. Oleh karena itu, penerapan model pembelajaran kooperatif type Jigsaw diharapkan meningkatkan interaksi antara guru dan siswa dan antara siswa. Berdasarkan pada paparan di atas, penulis melakukan penelitian dengan judul "Peningkatan Kompetensi Menganalisis vektor dengan Model Pembelajaran Jigsaw pada Siswa Kelas X MIPA 4 Semester 1 Tahun Pelajaran 2019/2020”.

Belajar adalah suatu aktivitas mental/psikis yang berlangsung dalam interaksi aktif dengan lingkungan, yang menghasilkan perubahan-perubahan dalam pengetahuan, pemahaman, ketrampilan dan nilai sikap. Perubahan itu bersifat relatif konstan atau tahan lama (Winkel, 1987 : 34). Dalam proses pembelajaran diharapkan siswa mengalami perubahan baik aspek kognitif (pengetahuan),psikomotorik( ketrampilan) dan afektif ( sikap) menjadi lebih meningkat. Menurut Arikunto kategori nilai ulangan harian dapat dibuat kriteria seperti tabel berikut :

Tabel 1. Kriteria Nilai Ulangan Harian

\begin{tabular}{ccc}
\hline NO & Nilai & Kriteria \\
\hline 1 & $90-100$ & Sangat baik \\
2 & $80-89$ & Baik \\
3 & $70-79$ & Cukup \\
4 & $60-69$ & Kurang \\
5 & $0-59$ & Sangat kurang \\
\hline
\end{tabular}

Keaktifan siswa sangat diperlukan dalam belajar, karena pada prinsipnya belajar adalah berbuat untuk mengubah tingkah laku.

\begin{tabular}{|c|c|c|}
\hline $\mathrm{NO}$ & Nilai & Kriteria \\
\hline 1 & $<50$ & Kurang \\
\hline 2 & $50-74$ & Sedang \\
\hline
\end{tabular}




$$
\begin{array}{ccc}
3 & 75-90 & \text { Baik } \\
4 & 91-100 & \text { Baik sekali }
\end{array}
$$

Tujuan model pembelajaran kooperatif adalah keaktifan siswa dalam proses pembelajaran meningkat, siswa dapat menerima berbagai keragaman dari temanya sehingga prestasi belajar meningkat. Jigsaw adalah tipe pembelajaran kooperatif yang dikembangkan oleh Aronson's, (Aronson, Blaney, Stephen, Sikes, and SNAPP, 1978). Model pembelajaran ini didesain untuk meningkatkan rasa tanggung jawab siswa terhadap pembelajarannya sendiri dan juga pembelajaran orang lain. Dalam model pembelajaran type Jigsaw ini siswa dibagi menjadi dua kelompok yaitu "kelompok asal" dan "kelompok ahli”.

Vektor digambarkan dengan sebuah anak panah ang terdiri atas pangkal dan ujung.

-Penguraian Vektor

Setiap Vektor dapat di uraikan menjadi dua atau lebih vektor.

Nilai dan arah Vektor ditentukan degan cara berikut :

$\mathrm{V}^{2}=\mathrm{V}_{\mathrm{x}}^{2}+\mathrm{V}_{\mathrm{y}}^{2}$ dan $\tan \alpha=\mathrm{V}_{\mathrm{y}} / \mathrm{V}_{\mathrm{x}}$

-Vektor satuan

Vektor satuan adalah vektor yang di uraikan ke sumbu $X(i), Y(j)$ dan $Z(k)$ yang nilainya satu-satuan.

- Penjumlahan Vektor secara Geometri(grafis)

Cara Polygon dan cara jajar genjang

- Penjumlahan Vektor secara Analitis

Langkah-langkah: (a). Menguraikan vektor menjadi komponen vektor pada sumbu $\mathrm{X}$ dan sumbu Y. Menghitung besar komponen vektor $V_{x}=V \cos \alpha$, dan $V_{y}=V \sin \alpha$. (b). Menjumlahkan semua komponen vektor pada sumbu $X$ dan pada sumbu $Y . \quad R_{x}=\sum V_{x}$ dan $\mathrm{R}_{\mathrm{y}}=\sum \mathrm{V}_{\mathrm{y}}$ (c). Menghitung besar dan arah resultan $\mathrm{R}^{2}=\mathrm{R}_{\mathrm{x}}{ }^{2}+\mathrm{R}_{\mathrm{y}}{ }^{2}$ dan $\tan \alpha=\mathrm{R}_{\mathrm{y}} / \mathrm{R}_{\mathrm{x}}$

\section{Metodologi Penelitian}

Penelitian dilaksanakan 6 bulan di kelas X MIPA 4 SMA Negeri 1 Tawangsari Subjek penelitian adalah kelas X MIPA 4 SMA N 1 Tawangsari dengan permasalahanpermasalahan yang telah teridentifikasi pada saat observasi awal. Data penelitian berupa informasi tentang hasil belajar dan keaktifan siswa dalam belajar fisika. Teknik yang digunakan untuk mengumpulkan data meliputi: Observasi (mengamatai guru dan siswa) dan tes (hasil belajar fisika tentang vektor). Teknik analisa data menggunakan teknik analisis kritis. Prosedur PTK yaitu perencanaan, aksi atau tindakan, observasi dan refleksi. Pada penelitian ini direncanakan berlangsung 2 siklus.

\section{Hasil Penelitian}

Tabel 3. Rangkuman Data Keaktifan Siswa dan UH pada siklus 1

\begin{tabular}{lll}
\hline Aspek & Skor Keaktifan & Nilai UH \\
\hline Rata - rata & 62 & 76 \\
Simpangan Baku & 7,763 & 3,859 \\
Banyaknya siswa yang tuntas belajar & 26 siswa \\
Banyaknya siswa yang belum tuntas belajar & 10 siswa
\end{tabular}


Prosentase siswa yang tuntas belajar $72,22 \%$

Hasil Refleksi: (a). Keaktifan siawa dalam belajar fisika tentang vektor sudah meningkat dengan rata-rata skor 62. (b). Dari hasil ulangan harian pada siklus 1 ini, siswa yang tuntas belajar 26 siswa, sedangkan siswa yang belum tuntas belajar 10 anak dengan nilai rata-rata 76.

Tabel 4. Rangkuman Data Keaktifan Siswa dan UH pada siklus 2

\begin{tabular}{lcc}
\hline Aspek & Skor Keaktifan & Nilai UH \\
\hline Rata - rata & 76 & 80 \\
Simpangan Baku & 5,371 & 5,122 \\
Banyaknya siswa yang tuntas belajar & 36 siswa \\
Banyaknya siswa yang belum tuntas belajar & 0 siswa \\
Prosentase siswa yang tuntas belajar & $100 \%$ \\
\hline
\end{tabular}

Hasil Refleksi: (a). Keaktifan siswa dalam belajar fisika pada vektor sudah meningkat dengan rata-rata skor 76. (b). Dari hasil ulangan harian pada siklus 2 ini, semua siswa kelas X MIPA 4 sudah tuntas belajarnya dengan nilai rata-rata 80.

\section{Pembahasan}

Hasil akhir penelitian menunjukan bahwa proses pembelajaran dengan model jigsaw dapat meningkatkan kompetensi menganalisis vektor dengan model pembelajaran jigsaw pada kelas X MIPA 4 semester 1 SMA Negeri 1 Tawangsari tahun pelajaran 2019/2020. Peningkatan kompetensi menganalisis vektor setelah diberikan model pembelajaran jigsaw hasilnya sebagai berikut:

Tabel 5. Deskripsi data hasil penelitian tindakan kelas

\begin{tabular}{llcc}
\hline No & Hasil Tes & Siklus 1 & Siklus 2 \\
\hline 1 & Rata - rata & 76 & 80 \\
2 & Nilai Tertinggi & 85 & 95 \\
3 & Nilai Terendah & 70 & 76 \\
4 & Ketuntasan & $72,22 \%$ & $100 \%$ \\
\hline
\end{tabular}




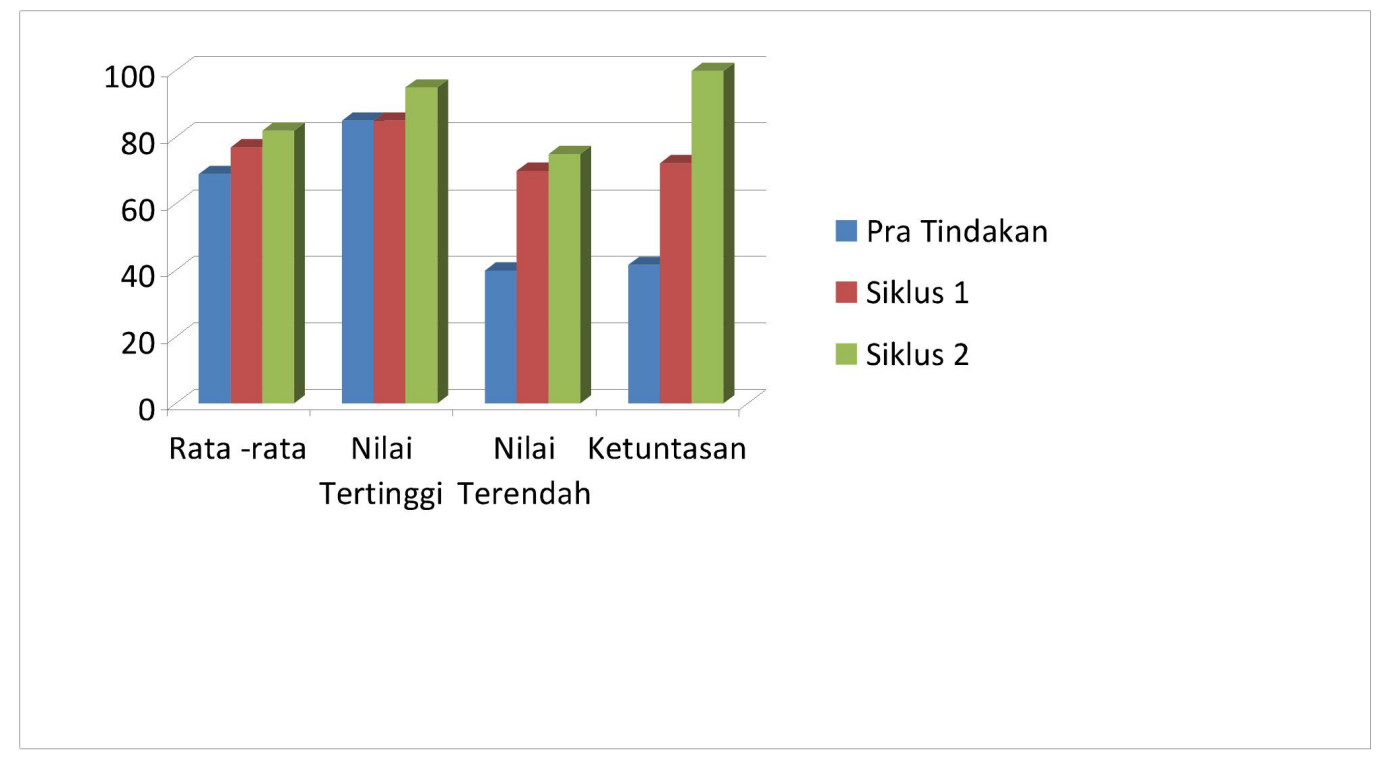

Gambar 1. Diagram data hasil penelitian tindakan kelas.

Keaktifan siswa mengalami peningkatan pada kompetensi menganalisis vektor setelah diberikan pembelajaran dengan model. Hasilnya sebagai berikut :

\begin{tabular}{cccc}
\multicolumn{4}{c}{ Tabel 6. Deskripsi data keaktifan Siswa } \\
\hline Aspek & $\begin{array}{c}\text { Kondisi Pra } \\
\text { Tindakan }\end{array}$ & Siklus 1 & Siklus 2 \\
\hline Keaktifan Siswa & 49 & 61 & 75 \\
& (Kurang) & (Sedang) & (Baik)
\end{tabular}

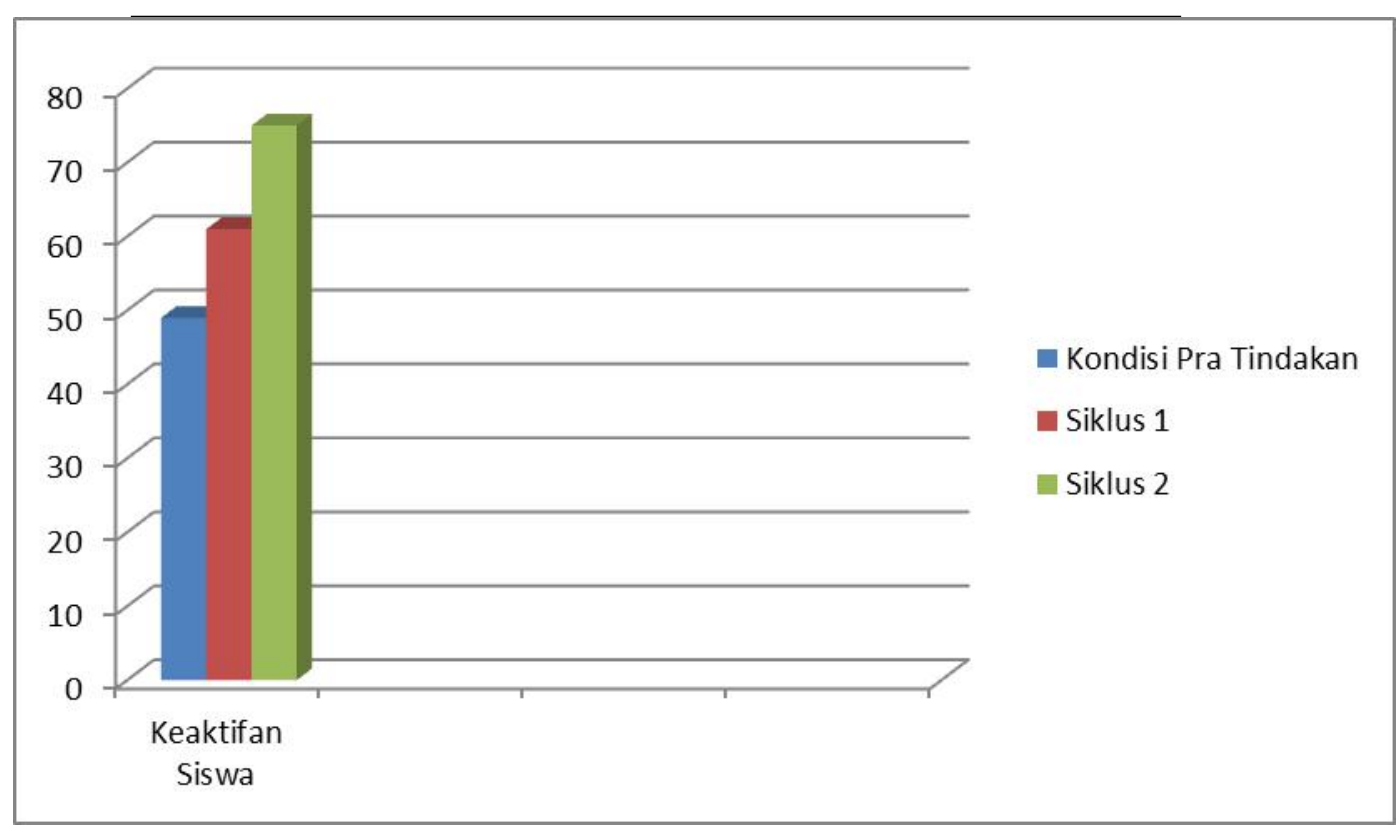

Gambar 2. Diagram Keaktifan Siswa Kondisi Pra Tindakan, Siklus 1, dan Siklus 2 
Model Pembelajaran Jigsaw dapat Peningkatan Kompetensi Menganalisis vektor pada Siswa Kelas X MIPA 4 Semester 1 Tahun Pelajaran 2019/2020. Saran kepada para pendidik jika ingin meningkatkan kompetensi siswa tentang menganalisis vektor maka gunakanlah pembelajaran jigsaw.

\section{Daftar Rujukan}

Abu Ahmadi \& Widodo s. (1991). Psikologi Belajar. Jakarta: Rineka Cipta Aqib Zainal. (2006). Penelitian Tindakan Kelas untuk Guru. Bandung : PT Yrama Widya Arikunto Suharsini dkk. (2006). Penelitian Tindakan Kelas. Jakarta : Bumi Aksara Bambang Ruwanto.(2016). Fisika SMA kelas X.Jakarta: Yudistira Depdiknas. (2003). Undang-undang RI Nomor 20, Sisdiknas. Jakarta : Depdiknas (2006). Model-model Pemebelajaran yang efektif. Bahan Sosisalisasi KTSP. Jakarta: Depdiknas

Departemen Pendidikan Nasional, Standar Kompetensi dan Kompetensi Dasar 2013 untuk mata pelajaran Fisika untuk SMA dan MA

Dimyati dan Mujiono. (2002). Belajar dan Pembelajaran. Jakarta : Rineka Cipta

Kanginan Marthin. (2008). Seribu Pena Fisika SMA Kelas XI. Jakarta, Erlangga

Lewin Kurt. (1990). “Action Reseach and Minorty Problems” 3rd ed. Victoria : Deakin University.

Muhibbin Syah. (1995). Psikologi Pendidikan Suatu Pendekatan Baru. Bandung : Remaja Rosdakarya

Ruwanto Bambang. (2016). Fisika SMA kelas X. Jakarta: Yudistira

Slameto. (1995). Belajar dan Faktor-faktor yang mempengaruhinya. Jakarta: Rineka Cipta.

Sutama. (2013). Modul PLPG Penelitian Tindakan Kelas dan Penulisan Karya Ilmiah. Surakarta : Badan Penerbit FKIP UMS

Winkel.W.S,. (1991). Psikologi Pengajaran. Jakarta: Grasindo

Hariyani Suprapti. (2019). Peningkatan Aktivitas dan Hasil Belajar IPA Materi Sistem Ekskresi Manusia melalui Model Pembelajaran Discovery Learning dan Metode Eksperimen Siswa Kelas VIII G SMP Negeri 1 Boyolali pada Semester Genap Tahun Pelajaran 2018-2019. Jurnal Pendidikan, Volume 28, Nomor 3, November 2019, Hal: 339-352.

Suratno. (2020). Peningkatan Aktivitas dan Hasil Belajar Matematika Materi Barisan dan Deret Melalui Pendekatan SAVI Bagi Siswa Kelas XI IPS1 SMA Negeri 1 Tawangsari Semester 2 Tahun Pelajaran 2018/2019. Jurnal Pendidikan, Volume 29, Nomor 1, Maret 2020, Hal : $67-76$ 